\title{
UM MODELO DIDÁTICO DO GÊNERO TEXTUAL CRÔNICA JORNALÍSTICA
}

\author{
Ana Paula Altvater Santos ${ }^{1}$ \\ Marilúcia dos Santos Domingos Striquer ${ }^{2}$
}

\section{RESUMO}

Com o objetivo de conhecer as especificidades que caracterizam o gênero textual crônica jornalística, elaboramos um modelo didático do referido gênero, o qual apresentamos neste artigo. A escolha pela crônica ocorreu devido ao fato desse gênero tratar de temas que retratam o cotidiano, de acontecimentos presentes e de interesse da sociedade, temas que podem ser eixos organizadores do ensino e da aprendizagem da língua portuguesa em sala de aula da educação básica, pela aproximação das temáticas constituídas nas crônicas com a vida dos alunos. 0 aporte teórico-metodológico que conduziu nosso trabalho se formou a partir dos preceitos do Interacionismo Sociodiscursivo. Os resultados evidenciam características como: esfera e a prática social da qual participa o gênero, a função sócio-comunicativa e os elementos que formam a infraestrutura textual da crônica jornalística.

\section{PALAVRAS-CHAVE}

Crônica Jornalística. Gêneros textuais. Interacionismo Sociodiscursivo.

\section{A DIDACTIC MODEL OF THE TEXTUAL GENRE OF THE JOURNALISTC CHRONICLE}

\begin{abstract}
In order to know the specificities that characterize the textual genre of the journalistic chronicle, we elaborate a didactic model of this genre, which is presented in this article. The choice of the chronicle was due to the fact that this genre deals with topics that portray the everyday current events that are of interest for the society. These topics may function as an organizing axis for the teaching and learning of Portuguese in primary education, through the coverage of topics that deal with pupils' everyday life. The theoretical-methodological contribution that shaped our work draws upon the precepts of Sociodiscursive Interactionism. The results show characteristics such as: the social sphere and practices in which the genre participates, its socio-communicative function and the elements that form the textual infrastructure of the journalistic chronicle.
\end{abstract}

KEYWORDS

Journalistic Chronicle. Text genres. Sociodiscursive Interactionism.

1 Graduanda do Curso de Letras/Inglês da Universidade Estadual do Norte do Paraná (UENP). Bolsista do Programa Institucional de Bolsa de Iniciação à Docência (PIBID/UENP), subprojeto Letras/Português-CJ.

2 Doutora em Estudos da Linguagem pela Universidade Estadual de Londrina (2013), Professora Adjunta da Universidade Estadual do Norte do Paraná (UENP), campus Jacarezinho e professora permanente do Programa de Mestrado Profissional em Letras - PROFLETRAS/UENP. 


\section{Introdução}

Estudar os gêneros não é um assunto novo. Platão já realizou estudos em busca de determinar noções básicas a respeito dos diferentes textos (MASCUSCHI, 2002). Com o tempo, os estudos se centravam em classificar as obras literárias a partir dos gêneros que as caracterizavam. Já em meados do século $X X$, segundo Mascuschi, os estudos sobre os gêneros tornaramse cada vez mais difundidos e amplos, assim, afirma o autor que o que ocorreu foi que "um conceito que achou o seu tempo" (MARCUSCHI, 2008, p. 148). A partir dos estudos de Bakhtin, os gêneros passaram a ser definidos como fenômenos decorrentes das necessidades de comunicação dos indivíduos, formando-se a partir das manifestações culturais e das formas cognitivas de ação social. Portanto, os gêneros são fenômenos sócio-discursivos presentes na vida das pessoas.

Nesse sentido, interessamonos em conhecer as especificidades características do gênero textual crônica jornalística. A escolha pela crônica ocorreu devido ao fato desse gênero tratar de temas que retratam o cotidiano, de acontecimentos presentes e de interesse da sociedade, temas que podem ser eixos organizadores do ensino e da aprendizagem da língua portuguesa em sala de aula da educação básica, pela aproximação das temáticas constituídas nas crônicas com a vida dos alunos.

Importante destacar ainda que ao delimitarmos a crônica jornalística como objeto de estudo, o fazemos pautadas nas definições de Tuzino para quem esse é um gênero "híbrido, é um ponto de intersecção entre o jornalismo e a literatura" (TUZINO, 2009, p. 1). Assim, embora a crônica faça parte da esfera social jornalística, tendo a função de noticiar, comentar acontecimentos cotidianos junto à exposição da opinião do autor sobre a questão, esse gênero permite ao seu autor uma maneira diferente de produzir relatos, com o emprego de uma linguagem e abordagem literária.

Dessa forma, nosso objetivo, neste trabalho, é elaborar um modelo didático do gênero textual crônica, a fim de evidenciar suas especificidades sóciocomunicativas, 
e linguísticas. Para tanto, norteamo-nos pela engenharia didática proposta pelo Interacionismo Sociodiscursivo (ISD), considerando que um dos instrumentos para se conhecer um determinado gênero é a construção de um modelo didático. Os modelos didáticos são ferramentas que facilitam que os pesquisadores conheçam e compreendam as características que formam um gênero (BARROS, 2012).

\section{Fundamentação teórica}

Estudioso do conceito de gênero do discurso estabelecido por Bakhtin, Marcuschi expõe que os gêneros são elaborados e determinados pelas esferas sociais, também chamadas de campos da atividade humana. 0 que corresponde a compreender que os gêneros possuem certas características fixas, uma vez que estão vinculados às esferas das quais participam e, por esse motivo, podem ser flexíveis, pois assumem configurações estruturais relacionadas à situação comunicativa (esfera ou campo) da qual participa. Isso ocorre, porque os gêneros estão sempre ligados às necessidades e ao funcionamento da sociedade. Assim, os gêneros "caracterizamse como eventos textuais altamente maleáveis, dinâmicos e plásticos" (MARCUSCHI, 2002, p. 19), surgem e se integram às culturas por serem essenciais para o desenvolvimento do homem na sociedade. Por esse motivo, os gêneros são uma "forma de ação social", exercendo papel imprescindível na elaboração de uma estrutura comunicativa, logo, fazem parte da história da sociedade (MILLER apud MARCUSCHI, 2002, p. 19).

Contudo, definir o que são os gêneros é uma tarefa bastante complexa, exatamente porque podem sofrer mudanças, transformações, adaptações a partir das esferas das quais participam e das práticas sociais que são realizadas dentro das esferas (MARCUSCHI, 2008). Por isso, é preciso que um gênero seja analisado considerando sua(s) função(ões) comunicativa(s) tomando como ponto de partida a esfera na qual o gênero está inserido, o objetivo da interação, o querer dizer do autor, o contexto da interação, a temática tratada no texto, chegando às análises 
dos três elementos que, segundo Bakhtin, formam o enunciado: o tema, a construção composicional e o estilo.

Sobre esses três elementos, “o tema é o conteúdo inferido com base na apreciação de valor, na avaliação, no acento valorativo que o locutor (falante ou autor) lhe dá" (ROJO, BARBOSA, 2015, p. 87). Nessa direção, o tema é sempre único e irrepetível pelo fato que está intimamente vinculado aos interlocutores, ao momento e ao lugar da enunciação e da situação comunicativa da qual o texto participa. Por exemplo, a crônica jornalística trata de temas cotidianos que tenham relação com os acontecimentos atuais na sociedade ou de temas que são contraditórios historicamente e que por algum motivo voltaram a ser discutidos no momento da produção do texto.

Com relação ao estilo, Rojo e Barbosa defendem que "o estilo são as escolhas linguísticas que fazemos para dizer o que queremos dizer ('vontade enunciativa'), para gerar sentido desejado" (ROJO; BARBOSA, 2015, p. 92 - grifo das autoras). Essas escolhas referemse à escolha do léxico, da sintaxe, do tempo verbal, dos mecanismos textuais e enunciativos a serem empregados no texto. Portanto, o estilo não é o estilo do autor, é do gênero. Contudo, é importante fazer menção ao fato de que alguns gêneros são mais livres para o emprego de um estilo que é próprio do autor, como os gêneros que emergem da esfera literária, onde também está inserida a crônica, por ser híbrida, como foi afirmado (BAKHTIN, 2003). Por sua vez, os gêneros das esferas sociais como a jurídica, a acadêmica, a militar suportam poucas variações específicas do estilo, por apresentarem uma estrutura mais fixa e formal.

0 terceiro elemento que compõe o gênero é a construção composição (BAKHTIN, 2003) e esse elemento "está relacionado ao que a teoria textual chama de '(macro/super) estrutura' do texto, à progressão temática, à coerência e coesão do texto" (ROJO; BARBOSA, 2015, p. 95 - grifo das autoras). Tendo essas definições como princípio teórico, nos norteamos pelos procedimentos de análise de textos sugerida pelo Interacionismo Sociodiscursivo (BRONCKART, 2009). Dessa forma, 
para construir o modelo didático da crônica jornalística, nos pautamos no dispositivo didático construído por Barros (2012), o qual consiste em uma tabela que contempla uma sequência de perguntas que direcionam e auxiliam o pesquisador na análise do gênero. Ao alcançar as respostas às questões apresentadas nos dispositivos, as que são pertinentes ao gênero em pesquisa, o pesquisador conhece as principais características que formam o gênero.

Segundo Barros, a modelização de um objeto de ensino é importante não somente para pesquisadores, mas também para a formação do professor de línguas, pois a modelização "pode responder às perguntas o que ensinar? Por que ensinar?" E ainda "oferece condições para a produção de sequências didáticas" (BARROS, 2012, p. 17 - grifos da autora). A sequência didática é uma ferramenta para o ensino e aprendizagem de uma língua formada por um conjunto de atividades.

0 primeiro passo do procedimento,seguindoaproposta do ISD, é reunir um conjunto de textos, exemplares do gênero em questão, e sobre os exemplares realizar um levantamento das definições feitas por especialistas e depois analisar "o contexto de produção e as três camadas do folhado textual: a infraestrutura geral do texto, os mecanismos de textualização e os mecanismos enunciativos" (BARROS, 2012, p. 16), a partir das questões que formam o dispositivo elaborado por esse autor, que reproduzimos a seguir. 
Quadro 1: Dispositivo didático elaborado por Barros (2012)

\begin{tabular}{|c|c|}
\hline \multicolumn{2}{|r|}{ ELABORAÇÃO DE MODELO TEÓRICO/DIDÁTICO DO GÊNERO } \\
\hline & Perguntas para direcionar a modelização do gênero \\
\hline $\begin{array}{l}\text { Elementos que } \\
\text { formam as } \\
\text { características } \\
\text { contextuais }\end{array}$ & 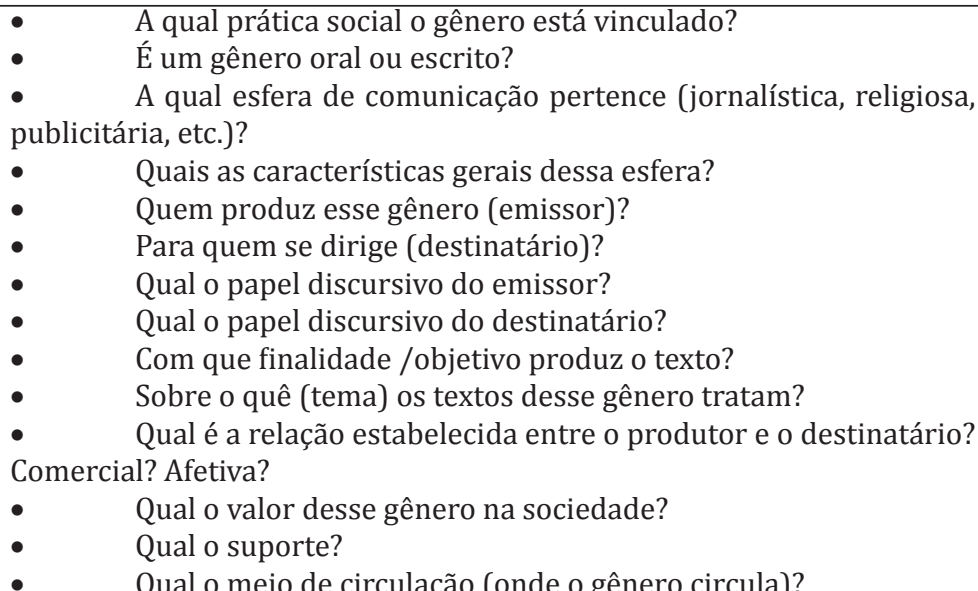 \\
\hline $\begin{array}{l}\text { Elementos que } \\
\text { formam as } \\
\text { características } \\
\text { discursivas }\end{array}$ & $\begin{array}{l}\text { - } \\
\text { explicitamente ao interlocutor, tenta manter um diálogo mais próximo } \\
\text { com o interlocutor, explica o tempo/espaço da produção)? } \\
\text { - } \quad \text { É um expor teórico (não deixa marcas de quem fala, para quem } \\
\text { fala, de onde e quando fala)? } \\
\text { - } \quad \text { É um narrar ficcional? } \\
\text { - } \quad \text { É um narrar acontecimentos vividos (relato)? } \\
\text { se configura? É dividido em partes? Tem título/subtítulo? É assinado? } \\
\text { Qual a sua extensão aproximada? Acompanha fotos/figuras? Quais as } \\
\text { características gerais? } \\
\text { - } \quad \text { Como são organizados os conteúdos no texto? Em forma de } \\
\text { lista? Versos? Prosa? } \\
\text { - } \quad \text { Qual o tipo de sequência predominante? Sequência narrativa? } \\
\text { Descritiva? Explicativa? Argumentativa? Dialogal? Injuntiva? }\end{array}$ \\
\hline
\end{tabular}




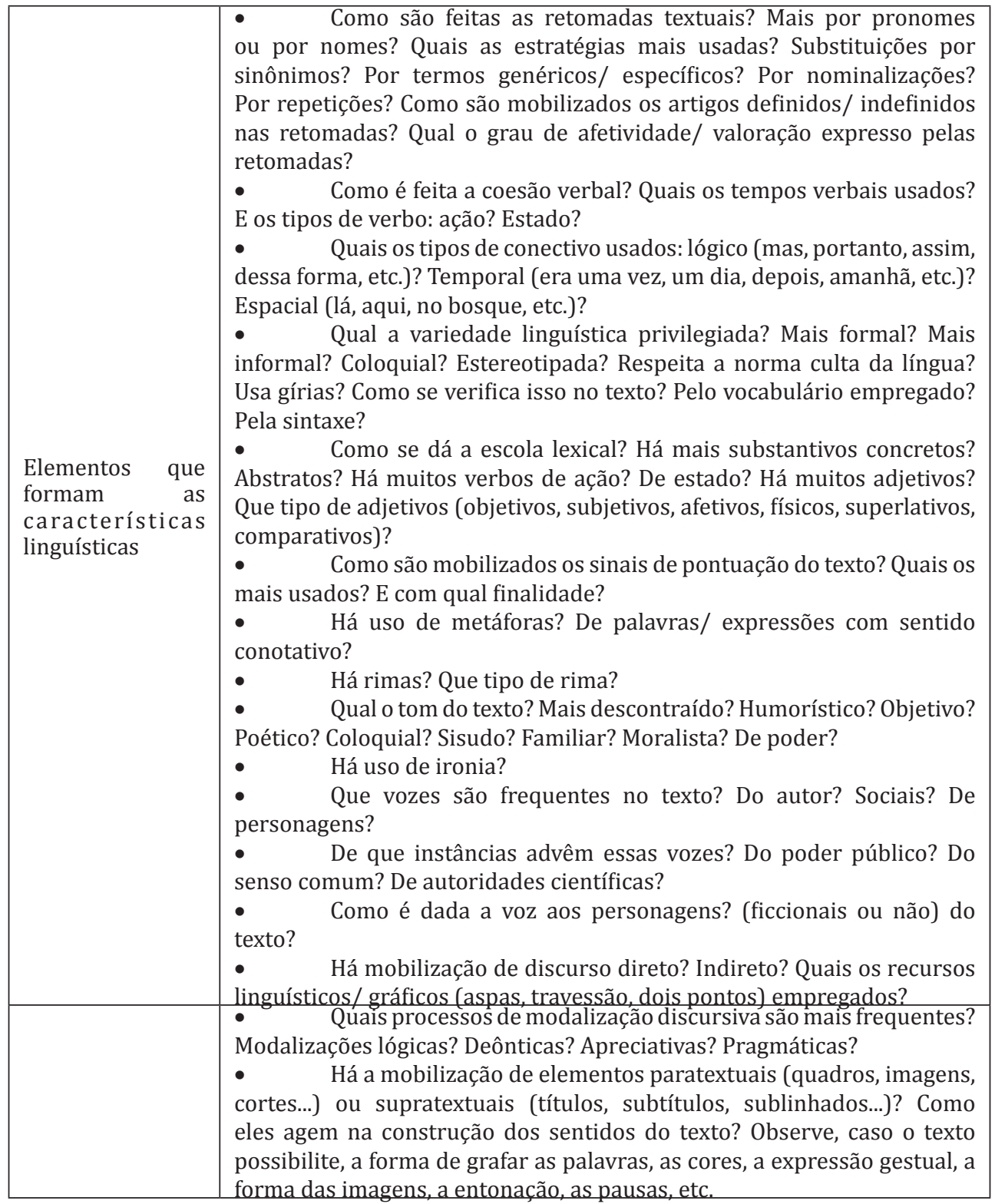

Fonte: quadro adaptado a partir do Dispositivo Didático, elaborado por Barros (2012). A adaptação ocorreu devido ao fato de que nem todas as perguntas que formam o dispositivo se direcionaram ao nosso gênero em específico.

\section{0 modelo didático da crônica jornalística}

Para a construção de um mencionado, é necessário um levantamento das definições realizadas por especialistas 
respeito do gênero em questão e, em nosso caso, recorremos aos estudos de Lima (2010), Tuzino (2009) eCosta (2008), entreoutros, pesquisadores do gênero crônica jornalística. Conforme Lima, em uma perspectiva etimológica, a denominação crônica está ligada à palavra grega chronos (tempo), do latim Chronica. Muitos dicionários definem crônica pelo significado de "cronos": acontecimentos alinhados em ordem cronológica. Por esse aspecto, trata-se de um gênero que acompanhou as transformações da humanidade devido à sua origem antiga, a qual retoma a idade média. "Na Idade Média, esse gênero textual tinha como finalidade narrar o maravilhoso e o lendário, eram os chamados cronicões medievais" (LIMA, 2010, p. 3). Contudo, a crônica teve seu momento de maior importância quando no Humanismo português, durante o reinado de D. Duarte Fernão Lopes, foi nomeado um "cronistamor do Reino" que passou a ser considerado um escritor profissional de crônicas, as quais tratavam da "verdade crua", ou seja, relatavam os acontecimentos reais do século XV. Existem registros de apenas três das crônicas de Fernão Lopes: Crônica de el-rei D. Pedro, Crônica de el-rei D. Fernando e Crônica de el-rei D. João (LIMA, 2010).

No Brasil, a crônica manteve a característica de ser um registro cronológico dos fatos. Com os investimentos de Portugal nas grandes navegações, iniciou-se uma nova era de acontecimentos históricos. Um deles foi a vinda dos portugueses para o Brasil, registrada em uma carta que, segundo esse autor, era de autoria de Pero Vaz de Caminha, a qual "além de conter relato da 'descoberta' do Brasil configura-se como a primeira crônica nacional" (TUZINHO, 2009, p. 5 - grifo das autoras).

A caracterização da carta de Caminha como uma crônica ocorre porque seu autor conseguiu recriar no texto exatamente o que estava ocorrendo no momento da produção do mesmo, relatando, assim, os acontecimentos e ao mesmo tempo descrevendo paisagens de forma subjetiva, com o emprego de linguagem literária. A autora defende ainda que muitas outras cartas produzidas para informar a corte portuguesa 
sobre o que ocorria no Brasil se configuram da mesma forma, o que fez nascer a crônica nacional (TUZINO, 2009).

Ao longo do tempo, o gênero foi adquirindo outras características e se estabelecendo na esfera jornalística:

No jornalismo brasileiro a crônica é um gênero plenamente definido. Sua configuração contemporânea permitiu a alguns estudiosos proclamarem que se trata de um gênero tipicamente brasileiro, não encontrado equivalente na produção jornalística de outros países (MELO, 1985, p. 111).

Embora com destaque na publicação em jornais, após alguns anos, a crônica passou a ser publicada também em revistas, sites e livros, e assim pode ser definida como um "gênero literário produzido essencialmente para ser vinculado na imprensa, seja nas páginas de uma revista, seja nas de um jornal" (COSTA, 2008, p. 72). A finalidade do gênero seria a de atrair os leitores dos veículos de comunicação, jornais, revistas, sites, para refletir sobre os acontecimentos a partir da perspectiva de um indivíduo que além de relatar fatos, opina sobre eles, sem um compromisso com o estritamente informativo.
Conhecida as definições da crônica, nos atemos à tabela de dispositivo didático elaborada por Barros e analisamos um conjunto de cinco crônicas que formam nossa coletânea de exemplares do gênero, a saber: duas crônicas de Drauzio Varella intituladas Glúten, lactose e outras modas e Mal posso acreditar que as festas acabaram; duas crônicas de Luiz Felipe Pondé, intituladas Falta de grana mata o amor porque ele perece diante da falta de hotizontes e Abandonados, 'os burros' sentem que seu esforço cotidiano não tem valor; e uma crônica de Gregório Duvivier, 0 Carnaval de rua é um milagre que aconteceu apesar de tudo e todos. Todos esses textos foram publicados no jornal online Folha de S. Paulo.

A prática social da qual faz parte a crônica jornalística é a ação de debater, refletir, expor a opinião de um sujeito a respeito de fatos do cotidiano social. Por exemplo, a crônica de Pondé, publicada em $16 / 01 / 2017$, relata a rebelião que aconteceu em um presídio do Rio Grande do Norte, no início daquele mês, resultando na morte de dezenas de presos e indignando a sociedade pela violência dos 
assassinatos. Ao mesmo tempo, o texto expõe a opinião do autor a respeito do assunto, o que pode ser exemplificado pelo trecho:

Passado o frenesi da indignação com o ocorrido nas prisões, podemos pensar um pouco sobre aquele inferno. Digo de cara que não acredito na indignação regada a queijos e vinhos. Vamos aos argumentos mais óbvios (e nem por isso menos verdadeiros), aos menos óbvios. Chegando mesmo aos que parecem obscuros aos inteligentinhos (PONDÉ, 2017).

Outro exemplo de como a opinião do autor está inserida no texto:

Óbvios: o Estado brasileiro é canalha, irresponsável, os dirigentes mentem, não estão nem aí para a vida dos presos (nem de ninguém), prender todo mundo num cubículo de lata é querer que se matem, o crime organizado cresce em meio ao vácuo do poder público, há uma crise no sistema prisional, há corrupção, as autoridades não fazem diferença entre um ladrão de galinha e um serial killer, pobre e preto sempre vai mais preso do que branco coxinha. Tudo verdade (PONDÉ, 2017).

Sobre a crônica ser um gênero oral ou escrito, podemos afirmar que se trata de um texto escrito, o que pode ser confirmado, no caso de nosso corpus, por serem textos publicados no site do jornal Folha de São Paulo, que é uma reprodução do jornal impresso feita em meio virtual (TUZINO, 2009). Por sua vez, para Costa (2008), a crônica é um gênero literário que se publica na imprensa e pertence à esfera literária por estar vinculada tanto ao jornal impresso quanto ao virtual, pertencendo também à esfera jornalística.

Sobre os interlocutores inseridos na interação proposta pela crônica, os exemplos de crônicas analisadas neste trabalho não foram produzidas por um jornalista ou por pessoas que estritamente estão ligadas a essa mídia, essa não é uma questão que valida a autoria, tanto porque nem todos os gêneros publicados na esfera jornalística são de autoria de jornalistas ou de profissionais ligados diretamente à área. As crônicas podem ser escritas por diferentes profissionais, contudo, a legitimação da autoria, isto é, o papel social do autor é instituído na ligação do tema tratado no texto e a formação acadêmica, profissional ou experiencial daquele que o produz. Como é o caso de Dráuzio Varela, Luiz Felipe Pondé, e Gregório Duviver, que são os autores físicos das crônicas em 
análise e ocupam papeis sociais que dão autoridade no tratamento do tema e sobre as opiniões emitidas por eles (BARROS, 2012).

Dráuzio Varela é formado em medicina, sendo médico atuante na sociedade, e sua crônica trata do tema: saúde. Luiz Felipe Pondé é filósofo e escritor e os temas de suas crônicas são: comportamento, religião e ciência. Gregório Duvivier é ator e escritor e trata, na crônica em análise, do tema carnaval que é um assunto mais corriqueiro que pode ser tratado por uma parcela maior de pessoas, sem a necessidade e uma formação específica no assunto. Nesse sentido, as experiências pessoais de Duvivier dão legitimidade à autoridade e à autoria do texto. Exemplo de como o autor está inserido no acontecimento em debate por experiências pessoais:

Quando era pequeno, minha mãe me fantasiava de pirata e saímos pela cidade procurando um bloquinho, E não era fácil encontrar um. Rodávamos a cidade inteira. De repente, ouvia, ao longe, o som de um surdo. Íamos correndo em direção a ele como quem caça um passarinho (DUVIVIER, 2017).

Sobre quem são os destinatários do gênero, nossos exemplares têm um público específico, que é levado em consideração por seus autores: os leitores do jornal impresso e do online da Folha de São Paulo. Importante destacar que as mídias realizam pesquisas e por isso conhecem quem são seus leitores, o que vai direcionar os cronistas na escolha da temática, no emprego da linguagem, tipo de argumento, organização da sintaxe, entre outros aspectos que se adequem ao público.

No que se refere aos elementos que formam a estrutura discursiva do gênero, o tipo de discurso em predominância (BARROS, 2012) é o expor interativo, com a marcação da primeira pessoa do discurso, como, por exemplo, no seguinte trecho da crônica de Pondé (2017), onde o autor se reporta diretamente ao interlocutor: "Imagine que seu pai deixou sua mãe por uma mulher 20 anos mais nova do que ele, e que ele teve um filho com ela"; ou na crônica de Drauzio Varella (2017): "Perdido na selva de informações desencontradas, o que você deve fazer, leitor? Coma frutas, saladas e verduras com liberalidade; do resto, de tudo um pouco. Procure comer o que sua avó considerava comida". 
Importante ainda o destaque de que os autores podem estar inseridos no texto de forma direta, como personagens, o que se justifica diante do gênero tratar de questões reais. Como é o caso da crônica de Duvivier, supracitado, em que o autor conta sua experiência com o carnaval.

A estrutura geral da crônica envolve: título; texto propriamente dito, que geralmente tem curta extensão; o que acontece, por ser publicado em jornal; e a assinatura do autor (apresentação do nome, que pode vir logo depois do título ou no final do texto). Em nossos exemplares verificamos que três deles possuem imagem ilustrativa, o que faz com que a imagem seja um recurso opcional do autor ou da editoração do jornal. A sequência argumentativa é a predominante no gênero, uma vez que é um texto opinativo, como pode ser comprovado na crônica de Pondé:

Devemos escapar da armadilha comum de pensar que assumir um preço para o afeto implica ser uma pessoa interesseira. Claro que esse caso óbvio também existe. Penso em pessoas motivadas pelo afeto mesmo e que, tristemente, às vezes, se batem com o limite material delas. Não era outra coisa que o grande Nelson Rodrigues tinha em mente quando dizia que dinheiro compra até amor verdadeiro (PONDÉ, 2017).

Na crônica de Dráuzio Varella, publicada em 07/02/2017, intitulada Glútem: lactose e outras modas, o autor apresenta, em alguns momentos, também a sequência explicativa, visto que precisa fazer com que o leitor entenda como funciona os mecanismos de saciedade do cérebro, o que não é uma questão de compreensão do senso comum. Exemplo:

A fartura trouxe o exagero. Um cérebro com circuitos de neurônios moldados em tempos de penúria não desenvolveu mecanismos de saciedade, capazes de frear os impulsos viscerais despertados pela fome, antes de nos empanturrarmos até passar mal de tanto comer (VARELLA, 2017).

E sobre os elementos que formam o estilo do gênero (BAKHTIN, 2003; BARROS, 2012), as retomadas textuais são realizadas mais fortemente por referenciação. Como o texto é curto, justamente por ser publicado em jornal, a referenciação é o mecanismo coesivo que organiza a temática. Exemplo: "De repente, ouvia, ao longe, o som de um surdo. Íamos correndo em direção a ele como quem caça um passarinho". 
Outro exemplo está na crônica de Pondé:

Para foucaultianos sofisticados, os bandidos são vítimas da ordem social repressiva e mostram em seu comportamento a doença social, por isso, os trancamos nas cadeias para "esquecermos" de nossa patologia social. Esse tom surgiu em algumas indignações, mas com um certo cuidado porque essa moçada está um pouco assustada com a "revolta dos burros" (PONDÉ, 2017).

0 pretérito é o tempo verbal empregado na crônica no momento em que os autores relacionam fatos do passado para explicar, relacionar, contextualizar o que ocorre continuamente ou nos dias atuais, como podemos ver no trecho do texto de Pondé: "Algum tempo atrás, nesta coluna, escrevi que hoje em dia é difícil saber separar afeto de grana (referia-me especificamente ao amor entre pais e filhos, mas o tema vai além disso, tocando o amor romântico também)". Mas o tempo em predominância é o presente, justamente para tratar de acontecimentos atuais. Exemplo: "Hoje, um brasileiro de classe média tem acesso a refeições mais variadas e nutritivas do que as dos nobres nos castelos medievais" (VARELLA, 2017).
A linguagem empregada no texto é mais informal, porque há uma relação estabelecida de interação entreautor einterlocutor, conforme apresentado na discussão sobre o tipo de discurso que forma o gênero. Exemplos:

$\mathrm{E}$ as renas e o trenó? $\mathrm{E}$ as chaminés e os flocos de algodão que imitam neve? Do ponto de vista estético, convenhamos que as imagens utilizadas para criar o clima de Natal, além de impróprias para os trópicos, são cafonas, sobretudo (VARELLA, 2017) (grifo das autoras).

Quer outro exemplo? Você se casa com um cara que tem uma exmulher. Se ele der muita atenção para ela e se preocupar muito em deixá-la "bem materialmente" mesmo depois da separação, você vai, sim, achar que ele ainda a ama. Não minta sobre isso só pra ficar bem com o marketing do bem, que deixa o mundo ainda mais cretino do que ele já é normalmente (PONDÉ, 2017) (grifo das autoras).

0 trecho da crônica de Pondé demonstra ainda que a voz que prenomina nas crônica é a do autor/narrador, mas é possível o emprego de vozes de personagens, como na crônica de Duvivier:

Minha avó Ivna era compositora de marchinhas. Nenhuma delas fez muito sucesso fora de casa, mas lá dentro eram hit. "Funciona! Funciona! Funciona - que eu quero ver, quem não 
funciona não pode sobreviver!" Tinha uns sete anos quando perguntei a ela o que ela estava esperando que funcionasse, e ela respondeu: "O pinto. Tem uma idade que já não funciona mais" (DUVIVIER, 2017).

0 referido trecho de exemplificação nos leva ao destaque de mais uma característica da crônica que não está inserida em todos os textos que materializam o gênero, mas pode ocorrer e é comum: o emprego do humor.

\section{Considerações finais}

Tendo como objetivo compreender o gênero crônica jornalística, analisamos um conjunto de exemplares e os resultados apontam para especificidades como: a crônica possui o papel social de debater, refletir, expor a opinião do autor a respeito de fatos do cotidiano; é um gênero escrito, publicado em jornais impressos ou virtuais, ou em outros mídias; pertence as esferas literária e jornalística ao mesmo tempo; seus autores podem ser de diferentes áreas do conhecimento, os quais assumem papéis sociais relacionados a temática tratado no gênero; 0 destinatário está ligado ao veículo que publica o texto; o tipo de discurso predominante é o do expor interativo; no plano geral, o texto tem título, o texto geralmente pequeno e a assinatura do autor; alguns trazem imagem ilustrativa; a sequência predominantemente é a argumentativa; o texto se organiza pelo mecanismo coesivo da referenciação; com o tempo conjugado no pretérito e no presente; a linguagem empregada é mais informal. Dessa forma, os resultados de nossas análises revelam as principais especificidades sóciocomunicativas, discursivas e linguísticas do gênero textual crônica jornalística. Em decorrência, temos como, em um segundo momento, construir sequências didáticas para o ensino da língua portuguesa tendo como eixo organizador o gênero crônica e os elementos que o caracterizam como conteúdos específicos a serem ensinados.

\section{Referências}

BAKHTIN, M. Estética da criação verbal. Tradução Maria Ermantina Galvão G. Pereira. 4. ed. São Paulo/SP: Martins Fontes, 2003.

BARROS, E. M. D. Transposição didática externa: a modelização do gênero na pesquisa colaborativa. Raído, v. 6, n. 11, 2012, pp. 11-35. BRONCKART, J. P. [et al]. Atividade de 
linguagem, textos e discurso: por um interacionismo sociodiscursivo. Tradução Anna Rachel Machado e Péricles Cunha. 2. ed. São Paulo: EDUC, 2009.

COSTA, S. R. Dicionário de gêneros textuais. Belo Horizonte. Autêntica Editora, 2008.

DUVIVIER, G. "O Carnaval de rua é um milagre que aconteceu apesar de tudo e todos". In: Folha de São Paulo on line - 13/02/2017 - Colunistas. Disponível em https://goo.gl/ vweLPT. Acesso em 10/03/2017.

LIMA, S. A. 0 gênero textual crônica nas práticas escolares da leitura e da escrita. Maceió: EPEAL, 2010 MARCUSCHI, L. A. Gêneros textuais: definição e funcionalidade. In: DIONISIO, A. P.; MACHADO, A. R.; BEZERRA, M. A. (Orgs.). Gêneros textuais e ensino. Rio de janeiro: Lucerna, 2002.

MARCUSCHI, L. A. Produção textual, análise de gêneros e compreensão. São Paulo: Parábola Editorial, 2008. MELO, J. M. de. A Crônica. In: MELO, J. M. de. Jornalismo opinativo: gêneros opinativos no jornalismo brasileiro. Campos do Jordão: Mantiqueira, 1985.

PONDÉ, L. F. “Abandonados, 'os burros' sentem que seu esforço cotidiano não tem valor". In: Folha de São Paulo on line - 16/01/2017 - Colunistas. Disponível em https://goo.gl/ WEXxLD. Acesso em 10/03/2017. PONDÉ, L. F. "Falta de grana mata o amor porque ele perece diante da falta de horizontes". In: Folha de São Paulo on line - 30/01/2017 - Colunistas. Disponível em https://goo.gl/ nMnR9i. Acesso em 10/03/2017.

ROJO, R.; BARBOSA, J. P. Hipermodernidade, multiletramentos e gêneros discursivos. São Paulo. Parábola, 2015.

TUZINO, Y. M. M. Crônica: uma intersecção entre o Jornalismo e Literatura. Disponível em: https:// goo.gl/RRiQti. Acesso em 24/08/09. VARELLA, D. "Glúten, lactose e outras modas". In: Folha de São Paulo on line - 04/02/2017 - Colunistas. Disponível em https://goo.gl/ BjPbQm. Acesso em 10/03/2017.

VARELLA, D. "Mal posso acreditar que as festas acabaram". In: Folha de São Paulo on line - 07/01/2017 - Colunistas. Disponível em https:// goo.gl/NYdmwb. Acesso em 10/03/2017. 